\title{
Effect of Coffea canephora Aqueous Extract On Microbial Counts in Ex Vivo Oral Biofilms: A Case Study
}

Authors
Affiliations
Key words
Coffea canephora
Rubiaceae
antimicrobial activity
oral biofilm
chlorogenic acid
caffeine

received January 12, 2012

revised March 17, 2012

accepted March 20, 2012

Bibliography

Dol http://dx.doi.org/

10.1055/s-0031-1298435

Published online April 24, 2012

Planta Med 2012; 78: 755-760

(c) Georg Thieme Verlag KG

Stuttgart · New York .

ISSN 0032-0943

\section{Correspondence}

Dr. Andréa Gonçalves Antonio,

PhD

Pediatric Dentistry and

Orthodontics

Federal University of Rio de Janeiro

Rua Professor Coutinho Fróis

$500 / 301$

22620-360 Rio de Janeiro - R

Brazil

andreagantonio@yahoo.com.br
Andréa Gonçalves Antonio ${ }^{1}$, Natália Lopes Pontes lorio ${ }^{2,3}$, Adriana Farah ${ }^{4}$, Kátia Regina Netto dos Santos² Lucianne Cople Maia ${ }^{1}$

The affiliations are listed at the end of the article

\section{Abstract \\ $\nabla$}

In the present study, the ex vivo antimicrobial effect of brewed coffee was tested on oral biofilms. For this, unsweetened and sweetened (10\% sucrose) brewed light-roasted Coffea canephora at $20 \%$ was used in biofilms formed by non-stimulated saliva from three volunteers. After $30 \mathrm{~min}$ contact with unsweetened and sweetened brews, the average microorganism count in the biofilms

\section{Introduction}

$\nabla$

Despite the widespread use of different sources of fluoride, dental caries continues to be the single most prevalent and costly oral infectious disease worldwide [1]. Virulent biofilms that are strongly adherent to oral surfaces are a primary cause of infectious diseases in the mouth, including dental caries [2], which is a dietary- and biofilm-dependent disease associated with the frequent consumption of fermentable carbohydrates and with the shift in biofilm microbiota induced by the $\mathrm{pH}$ fall [3].

Biofilms formed in vivo are comprised of mixed flora, which are notoriously difficult to eradicate. It is important to recognize that bacteria present in a mature biofilm behave quite differently from their planktonic counterparts [4]. The treatment tion and/or elimination of bacterial accumulations in the retentive sites of the teeth by daily tooth brushing and frequent dental cleanings or prophylaxes [5]. However, many synthetic agents including chlorhexidine and cetyl pyridinium chloride, used widely in dentistry to inhibit bacterial growth, have been provoking antimicrobial resistance of oral microorganisms. Thus, the use of natural antimicrobial agents as an alternative therapy against oral pathogens has been widely investigated [6-9]. for biofilm-dependent disease requires the reduc- reduced by $15.2 \%$ and $12.4 \%$, respectively, with no statistical difference among them. We also observed a drop of microorganisms in the biofilms after treatment with sucrose solution at $5 \%$ compared to control (saline) and to sucrose at $1 \%$ and $3 \%$. In conclusion, Coffea canephora extract reduces the microbial count in oral biofilm, and our data suggest that sucrose concentration in coffee brew can influence its antimicrobial property against the referred biofilm.
Among natural products that have demonstrated antibacterial properties, coffee is the most popular in terms of consumption $[8,10,11]$. This opens a promising avenue of applications, since it is relatively safe and has a taste and odor largely appreciated [12].

Among many existing coffee species, the two most commercialized are Coffea arabica and Coffea canephora, and in a recent study, Antonio et al. [7] reported that Coffea canephora extracts exerted better performance in relation to inhibition of biofilm formation by Streptococcus mutans - a cariogenic bacterium, compared to Coffea arabica, since it is rich in polyphenols. In addition, the same authors [8] demonstrated in vitro that Coffea canephora beans also exerted influence on the deremineralization process of deciduous tooth fragments in the presence of an ex vivo mixed biofilm. Anila Namboodiripad and Kori [13] observed a reduction of teeth with decayed, missing and filled surfaces (DMFS) in a population with the habit of coffee consumption compared to others without the same custom.

Besides all the evidence involving the antibacterial activity of coffee against Streptococcus mutans $[7,8,11,14-16]$, studies clarifying the role of coffee on the microorganism reduction within the biofilm are still needed. In addition, in all parts of the world, coffee is largely consumed with sugar. However, there is no evidence that sweetened 
coffee extracts exert antibacterial activity. Therefore, the objective of this study was to determine if unsweetened and sweetened Coffea canephora extract effectively reduced the number of microorganisms in mixed ex vivo artificial biofilms. The null hypothesis was that Coffea canephora would not reduce the microbial count in the biofilm formed by oral microorganisms when compared to chlorhexidine gluconate, a potent antiplaque agent.

\section{Material and Methods}

$\nabla$

\section{Coffee extract and controls}

Beans of Coffea canephora cv. Conillon were used (voucher: Brasil, Estado do Espírito Santo, Distrito de Cachoeiro de Itapemirim, Fazenda Experimental de Pacotuba, INCAPER, A.G. Antonio, s/n ${ }^{\circ}-$ RFA 37915). The beans were roasted in a commercial spouted bed roaster (I-Roast), operating at a max. temperature of $220^{\circ} \mathrm{C}$, for $6 \mathrm{~min}$, to produce a light roasting degree (SCAA). Then, they were ground in a laboratory-scale mill to pass through a 0.46 mm sieve.

Unsweetened and sweetened aqueous coffee extracts at 20\%: an aqueous unsweetened coffee extract at $20 \%$ was obtained by a coffee brewing procedure, percolating $100 \mathrm{~mL}$ of pre-boiling $\left(95^{\circ} \mathrm{C}\right)$ Milli-Q purified water (Millipore Corporation) through $20 \mathrm{~g}$ of ground roast coffee. The extracts were filtered through Whatman \#1 qualitative filter paper (Whatman). The coffee sample and the roasting degree used in this study were selected based on a previous study [7], in which it presented the best results among 36 coffee extracts regarding its antibacterial effect against Streptococcus mutans. The sweetened coffee extract was prepared just like the first extract and sweetened with $10 \%$ sucrose.

Controls: Chlorhexidine gluconate (UFRJ Pharmacy) at $0.05 \%$ was used as a positive control, whereas Milli-Q purified water was used as a negative control. Milli-Q purified water with sucrose (Sigma-Aldrich) addition (10\%) was also used to treat the biofilm.

Characterization of phenolic compounds, caffeine, trigonelline, and sucrose of Coffea canephora extract The contents of caffeic acid and chlorogenic acids - caffeoylquinic acids (3-, 4-, and 5-CQA); 3-, 4-, and 5-feruloylquinic acids (3-, 4-, and 5-FQA); 3-, 4-, and 5-coumaroylquinic acids (3-, 4-, and 5CoQA); 3,4-, 3,5- and 4,5-dicaffeoylquinic acids (3,4-, 3,5-, and 4,5-diCQA), were determined by LC-DAD-ESI-MS and external synthesized standards, according to Farah et al. [17]. The contents of caffeine, trigonelline (Sigma-Aldrich), and sucrose were determined by LC-ESI-MS according to Perrone et al. [18]. Analyses were performed in triplicate.

\section{Analyses of aluminum and fluoride contents of the Coffea canephora extract}

For analysis of aluminium (Sigma-Aldrich), an aliquot of $3 \mathrm{~mL}$ from Coffea canephora extract at $20 \%$ was sampled and centrifuged $\left(3000 \times \mathrm{g}, 3 \mathrm{~min}, 4^{\circ} \mathrm{C}\right)$. The supernatant was treated with $250 \mu \mathrm{L}$ of $65 \%$ of $\mathrm{HNO}_{3}$. The solutions were analyzed by atomic absorption spectroscopy (Analyst 300; Perkin Elmer).

The fluoride content in the coffee extract was measured using an ion specific electrode, according to Lima and Cury [19]. Analyses were performed in duplicate.

\section{Volunteers and saliva samples collection}

The study was approved by the Local Ethics Committee (IESC UFRJ - Protocol number: 43/07). Young adult volunteers $(n=3)$ were recruited among graduated students attending the School of Dentistry and the School of Microbiology from a Federal University of Rio de Janeiro and gave their written informed consent to participate in the study. They were in good general and oral health, not making use of medication and had all natural teeth. Subjects were instructed not to consume food or beverages except for water during 1 hour before saliva collection. Moreover, none of them consumed coffee habitually. Non-stimulated saliva samples were collected after the volunteers spit into a graduated collection sterilized tube. Saliva produced in the first 30 seconds was discarded and then, it was collected for exactly 5 minutes [20]. During the collection period, the individuals remained comfortably seated in a ventilated and lighted room. Their mean DMFT (4.6) and mean whole saliva flow rate $(0.83 \mathrm{~mL} / \mathrm{min})$ were registered. The saliva samples, stored in melting ice, were immediately transferred to the microbiology laboratory for biofilm assay.

\section{Antimicrobial assays with artificial ex vivo biofilm}

The coffee activity on microbial counts in biofilms was achieved by reproducing ex vivo biofilms with human saliva [4]. Twenty microliters of non-stimulated saliva collected from each of the healthy donors $(n=3)$ were placed on $0.22-\mathrm{mm}$ membrane disks (diameter of $0.13 \mathrm{~mm}$ ) (Millipore). Each membrane was placed over plates containing BHI-S (brain heart infusion medium, from Difco; supplemented with hemin, menadione from Inlab, and yeast extract, obtained from Oxoid). The system was incubated anaerobically for $48 \mathrm{~h}$ at $37^{\circ} \mathrm{C}$. After biofilm growth, disks were collected and placed inside a glass flask, for $30 \mathrm{~min}$, containing $2 \mathrm{~mL}$ of the following substances: (i) coffee aqueous extract (CE, $20 \mathrm{mg} / \mathrm{mL}$ ); (ii) coffee aqueous extract $(20 \mathrm{mg} / \mathrm{mL}$ ) with sucrose at $10 \%$ (SCE); (iii) chlorhexidine $(0.05 \%)$ - positive control; (iv) Milli-Q water with sucrose at $10 \%$; and (iv) plain Milli-Q water negative control. This procedure was performed in duplicate ( Fig. 1). Then, the disks were briefly washed in sterile saline to rinse out the added substances, and the biofilm was extracted by vortexing the disks in $1 \mathrm{~mL}$ of sterile saline during 2 minutes. To enumerate viable cells, serial dilutions $\left(10^{-1}\right.$ to $\left.10^{-8}\right)$ were performed, and $50 \mathrm{~mL}$ of each dilution were streaked out on BHI-S agar (short plate) in triplicate. Plates were incubated anaerobically for $48 \mathrm{~h}$ at $37^{\circ} \mathrm{C}$ and then, $\mathrm{CFU} / \mathrm{mL}$ was counted. The activity of the coffee extracts on microbial biofilms was estimated by comparing the microbial population collected from the biofilms placed in the controls and the microbial population collected from the biofilms placed in coffee extracts.

\section{Sucrose endpoint for mixed oral biofilm growth}

Mixed biofilms were formed from human saliva in artificial membranes. The biofilm/membranes were transferred to test tubes $(\mathrm{n}=7)$, which contained saline solution (control) and sucrose $(1 \%, 3 \%, 5 \%, 7 \%, 10 \%$, and $20 \%)$. After the same treatment with the protocol described above for the antimicrobial assay with artificial biofilm, diluted samples $\left(10^{-1}\right.$ to $\left.10^{-8}\right)$ were inoculated onto a BHI-S agar plate and incubated anaerobically for $48 \mathrm{~h}$ at $37^{\circ} \mathrm{C}$. The number of CFU was calculated. The experiment was performed in duplicate. 


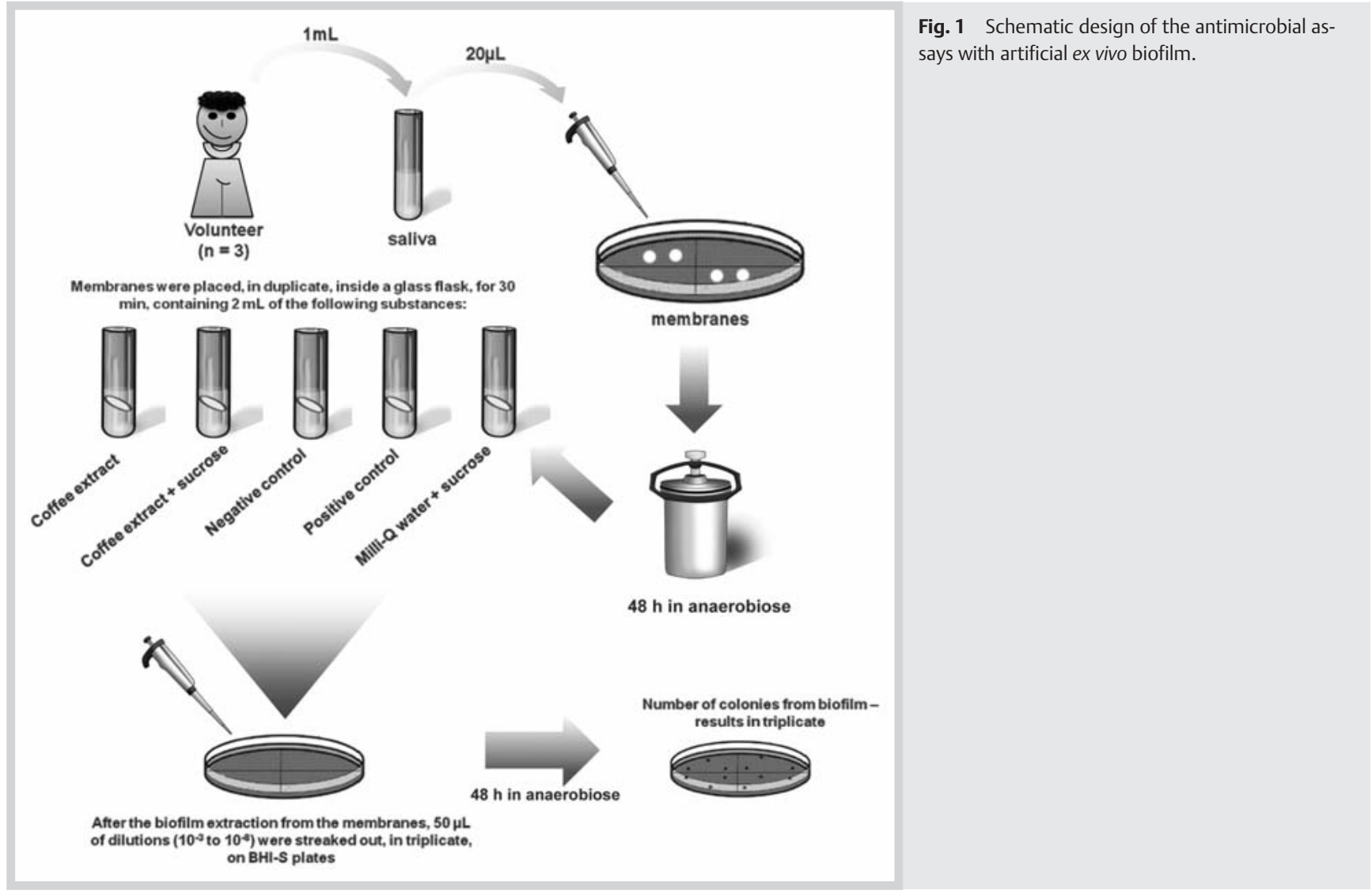

\section{Statistical analysis}

Data were analyzed using SPSS 17.0 Software (SPSS, Inc.). The normal distribution of the errors was checked with the ShapiroWilk's test for all response variables. The difference between the applied treatments was observed through the Kruskal-Wallis test followed by Mann Whitney for comparisons of substances twoby-two. Differences between means were considered significantly different when values were $\mathrm{p}<0.05$.

\section{Results and Discussion}

$\nabla$

Although fluoride remains the mainstay for the prevention of dental caries, additional approaches are required to enhance its effectiveness. Available antiplaque approaches are based on the use of broad-spectrum microbicidal agents, for example, chlorhexidine. Natural products offer a rich source of structurally diverse substances with a wide range of biological activities, which could be useful for the development of alternative or adjunctive anticaries therapies [1]. Coffee has demonstrated antibacterial properties against Streptococcus mutans $[8,11]$, which is the main agent of dental caries [21]. However, these studies observed such activity against planktonic cells. Biofilms are much more resistant to antimicrobial agents than cells in suspension [22]. In this context, artificial biofilms from non-stimulated saliva were prepared and then exposed to coffee extracts.

The contents of bioactive components of coffee extract such as phenolic compounds (chlorogenic acids and caffeic acid), sucrose, caffeine, and trigonelline are presented in $\odot$ Table 1. A succession of studies have been performed exploring the antimicrobial properties of coffee on different microorganisms $[7,10,11,23$,
Table 1 Contents of phenolic compounds, sucrose, caffeine, and trigonelline in Coffea canephora aqueous extracts.

\begin{tabular}{lc} 
Chemical compounds & Mean \pm SD \\
Phenolic compounds & $3650.8 \pm 74.0$ \\
\hline 3-CQA & $808.6 \pm 16.8$ \\
5-CQA & $1342.2 \pm 52.7$ \\
3-FQA & $136.6 \pm 7.0$ \\
4-CQA & $863.4 \pm 22.3$ \\
\hline 5-FQA & $78.7 \pm 6.5$ \\
\hline 4-FQA & $181.1 \pm 7.4$ \\
\hline 3,4-diCQA & $125.3 \pm 4.4$ \\
\hline 3,5-diCQA & $42.6 \pm 0.4$ \\
4,5-diCQA & $72.1 \pm 1.1$ \\
\hline CA & $87.3 \pm 35.0$ \\
Caffeine & $2110.0 \pm 0.4$ \\
\hline Trigonelline & $536.3 \pm 21.5$ \\
Sucrose & $74.7 \pm 1.4$
\end{tabular}

Results are shown as mean of triplicate analysis, expressed in $\mu \mathrm{g} / \mathrm{mL}$. CA = caffeic acid; $\mathrm{CQA}=$ caffeoylquinic acids; $\mathrm{FQA}$ = feruloylquinic acids; $\mathrm{diCQA}$ = dicaffeoylquinic acids

24], which can generate a significant improvement in managing several kinds of health disorders. The main compounds responsible for such activity in roasted coffee extracts are chlorogenic acids, caffeic acid, and caffeine. Other minor compounds described in the literature are trigonelline, $\alpha$-dycarbonil compounds, and protocatechuic acid $[7,10,11]$. In the present study, the chemical analyses of the coffee extract showed a large amount of chlorogenic acids, the presence of trigonelline and caffeic acid, and also caffeine, which probably exert inhibitory activity against the ex vivo biofilm. 


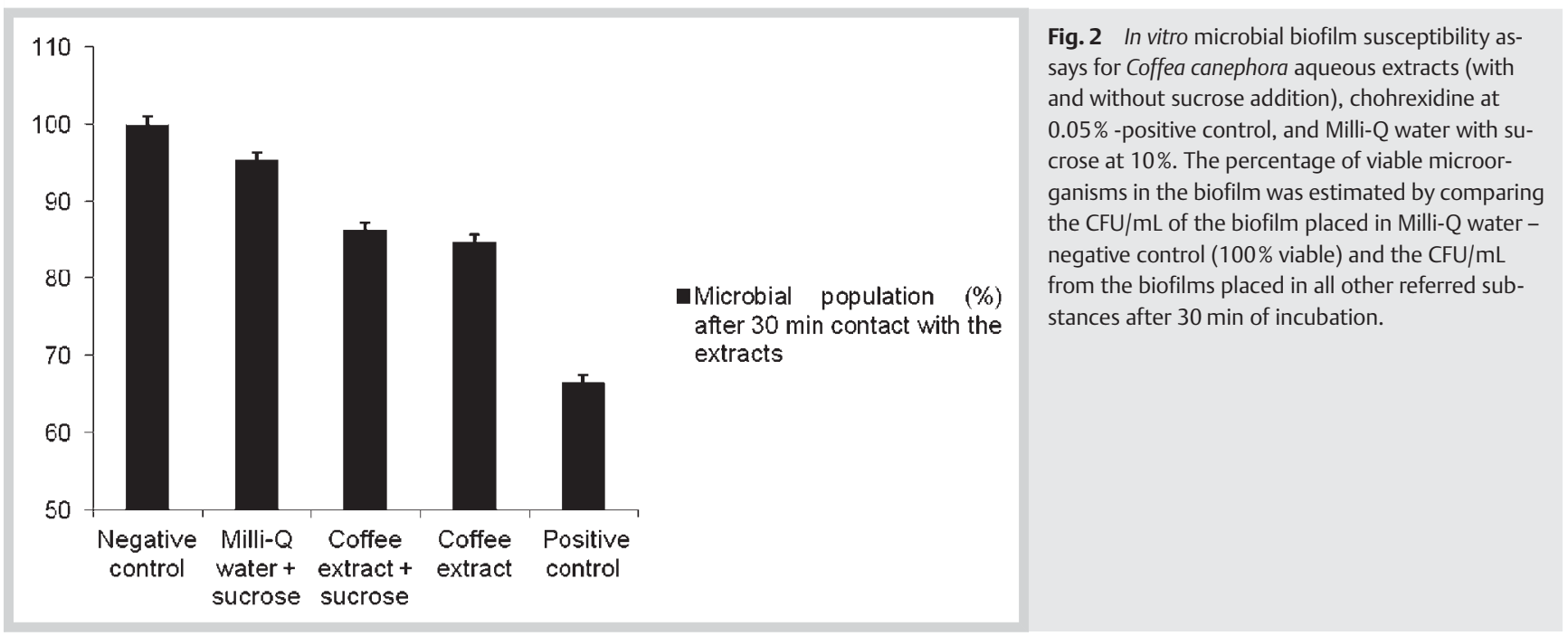

\begin{tabular}{llllll}
\multicolumn{5}{c}{ Microbial count from biofilm $\left(\mathbf{n} \times \mathbf{1 0 ^ { 6 }}\right) \pm$ SD $\left(\times 1 \mathbf{0}^{\mathbf{6}}\right)$ after treatment with } \\
Volunteer & NC & CE & SCE & PC & SMQ \\
\hline 1 & $15.08 \pm 6.81^{\mathrm{a}}$ & $1.90 \pm 0.65^{\mathrm{b}}$ & $2.62 \pm 0.70^{\mathrm{b}}$ & $0.03 \pm 0.00^{\mathrm{c}}$ & $6.23 \pm 0.64^{\mathrm{d}}$ \\
\hline 3 & $1.43 \pm 0.30^{\mathrm{a}}$ & $0.14 \pm 0.06^{\mathrm{b}}$ & $0.21 \pm 0.17^{\mathrm{b}}$ & $0.03 \pm 0.01^{\mathrm{c}}$ & $0.62 \pm 0.15^{\mathrm{d}}$ \\
\hline 3 & $2.56 \pm 0.91^{\mathrm{a}}$ & $0.24 \pm 0.10^{\mathrm{b}}$ & $0.51 \pm 0.14^{\mathrm{b}}$ & $0.02 \pm 0.00^{\mathrm{c}}$ & $0.87 \pm 0.14^{\mathrm{d}}$
\end{tabular}

Note: In rows, means values followed by distinct letters differ among them at a significant level of $5 \%$, considering the results independently, with respect to the individual microbiological characteristics of the volunteers

Aluminum and fluoride contents in Coffea canephora extract at $20 \%$ were $0.083 \pm 0.080 \mu \mathrm{g} / \mathrm{mL}$ and $0.018 \pm 0.000 \mu \mathrm{g} / \mathrm{mL}$, respectively. Aluminum has previously demonstrated antimicrobial activity against cariogenic streptococci as well as the normal oral flora and periodontal pathogens by significantly reducing the ability of streptococci to colonize on enamel surfaces and decrease the colloidal stability of oral bacteria $[25,26]$. According to Hayacibara et al. [27], there is a wide variety of natural beverages available with aluminum contents. In the present study, despite the low concentration of this compound in the coffee extract, this mineral associated to the presence of antibacterial coffee compounds, such as chlorogenic acids, trigonelline, and to a certain extent caffeine [7], could have exerted an effect on the reduction of the oral biofilm. In humans, mouth rinsing with aluminum solutions has shown to affect plaque accumulation and to alter the pathogenicity of the established plaque [28].

The evidence about the effect of fluoride on caries control is strongly supported by the literature $[29,30]$. We know that fluoride does not interfere with the factors responsible for the disease such as the biofilm accumulation [31]. However, some authors still affirm that it also affects to some extent the biological activities of cariogenic streptococci, for example, the inhibition of glucan synthesis and acidogenicity [32]. Although the fluoride contents were lower than the limits needed $(10 \mathrm{ppm})$ to affect bacterial metabolism [33], it is possible that like with aluminum, low amounts of fluoride would enhance the activity of other coffee components.

A reduction in biofilm microbial count was observed in the systems incubated with both extracts of Coffea canephora (SCE and $\mathrm{CE}$ ), with no statistical difference among them (○ Fig. 2). All microbial counting results were compared to the negative and pos- itive controls. The positive control was the most effective agent against the microorganisms from biofilm, reducing their count by about $32.1 \%(\mathrm{p}<0.05)$, whereas SCE and CE were able to reduce the CFU counts by $15.2 \%$ and $12.4 \%$, respectively, with no difference among them ( Table 2). A drop in biofilm microorganisms count was also observed after the treatment with Milli$\mathrm{Q}$ water with sucrose at $10 \%(\mathrm{p}<0.05)$ when compared to the treatment with the negative control ( Fig. 2). According to the literature $[31,34,35]$, the exposure to sugar can be considered a determinant factor in dental caries disease, especially if it occurs at a high frequency (e.g., more than 6 times/day). The difference between the results from the biofilm treatment with water and sweetened water, which demonstrated a drop of CFU counts from biofilm after treatment with the last one, is in contrast with our hypothesis according to which high levels of sucrose should have raised the ex vivo biofilm, since Vale et al. [36] affirmed that sucrose is able to significantly increase bacteria counts in dental biofilm.

In order to investigate the role of sucrose in the bacterium cell metabolism, we performed an additional experiment incubating membranes with the same mixed biofilm in sucrose solutions from $1 \%$ to $20 \%$. We observed that sucrose concentrations from $5 \%$ up to $20 \%$ were capable of reducing the number of bacteria colonies from biofilm compared to control (\$ Fig. 3). According to Lemos et al. [37], although the ability to survive for long periods of carbohydrate starvation is considered crucial for oral bacteria, sudden exposure to an excessive amount of sugar is also a major challenge for them. The rapid entry and degradation of sugars in cells can result in an accumulation of toxic levels of glycolytic intermediates, resulting in cell death. The authors believe that in the present in vitro conditions, the high levels of sucrose 


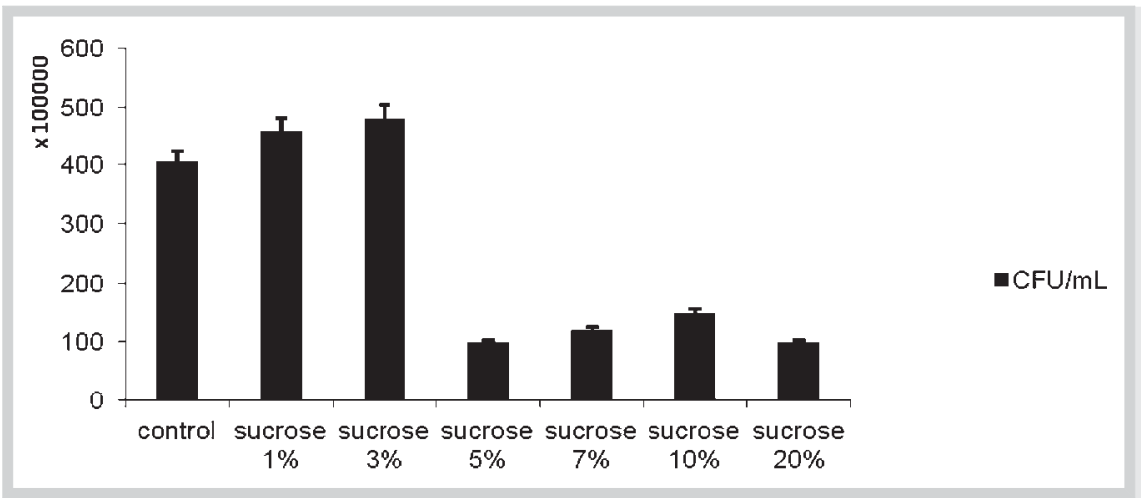

Fig. 3 Number of colonies forming units (CFU) using biofilm treated with increasing concentrations of sucrose and control.

provoked the drop of bacteria osmotic tolerance. Recently, we [7] tested a green (unroasted) Coffea canephora extract against $S$. mutans and observed that it did not inhibit the bacteria growth. This was attributed to the high sucrose concentration in the green coffee, which promoted the growth of the bacteria. However, the authors affirmed that the sucrose concentration of the extract was lower than $5 \%$. In this context, the results of the present work do not contradict the previous data, since we only observed the influence of sucrose on the reducing growth of bacteria when its concentration was from $5 \%$ up to $20 \%$.

The present results show that the Coffea canephora extract could reduce the microbial count in ex vivo oral biofilms by around $15 \%$. Considering that coffee is a natural ingredient that may be obtained in large quantities and at low cost it may be highly beneficial as an anticariogenic ingredient, mainly because no difference was observed among coffee extract with and without sucrose. However, as much as we have tried to mimic a real situation, these results were obtained from preliminary screening in in vitro circumstances. In addition, it is important to emphasize that the amount of sugar added to coffee varies considerably according to people's habits, which could influence the coffee properties against the oral biofilm reduction. Thus, further ex vivo/in vivo studies should be performed with the aim of investigating the influence of the sweetened coffee extract against oral biofilm.

\section{Acknowledgements}

$\nabla$

The authors acknowledge the scholarships and financial support from Fundação de Coordenação de Aperfeiçoamento de Pessoal de Nível Superior (CAPES), Fundação de Amparo à Pesquisa do Estado do Rio de Janeiro (FAPERJ), and Conselho Nacional de Pesquisa (CNPq). The help from Luciana Costa and Daniel P. Moreira with the chemical analysis as well as the technical support by Marina M. Moreira (UFRJ), Julio Cézar Paiva, and Aldo Mauri (INCAPER) are also appreciated.

\section{Conflict of Interest \\ $\nabla$}

The authors have no conflicts to declare.

\section{Affiliations}

${ }^{1}$ Departamento de Odontopediatria e Ortodontia, Faculdade de Odontologia, Universidade Federal do Rio de Janeiro, Rio de Janeiro, Brazil

2 Departamento de Microbiologia Médica, Instituto de Microbiologia Prof.

Paulo de Góes, Universidade Federal do Rio de Janeiro, Rio de Janeiro, Brazil

${ }^{3}$ Departamento de Ciência Básica, Universidade Federal Fluminense, Nova Friburgo, Brazil

${ }^{4}$ Instituto de Nutrição, Universidade Federal do Rio de Janeiro, Rio de Janeiro, Brazil

\section{References}

1 Jeon JG, Rosalen PL, Falsetta ML, Koo H. Natural products in caries research: current (limited) knowledge, challenges and future perspective. Caries Res 2011; 45: 243-263

2 Bowen WH, Koo H. Biology of Streptococcus mutans-derived glucosyltransferases: role in extracellular matrix formation of cariogenic biofilms. Caries Res 2011; 45: 69-86

3 Arthur RA, Del Bel Cury AA, Graner RO, Rosalen PL, Vale GC, Paes Leme AF Cury JA, Tabchoury CP. Genotypic and phenotypic analysis of S. mutans isolated from dental biofilms formed in vivo under high cariogenic conditions. Braz Dent J 2011; 22: 267-274

4 Alviano WS, Alviano DS, Diniz CG, Antoniolli AR, Alviano CS, Farias LM, Carvalho MA, Souza MM, Bolognese AM. In vitro antioxidant potential of medicinal plant extracts and their activities against oral bacteria based on Brazilian folk medicine. Arch Oral Biol 2008; 53: 545-552

5 Loesch WJ, Grossman NS. Periodontal disease as a specific, albeit chronic, infection: diagnosis and treatment. Clin Microbiol Rev 2001; 14: $727-752$

6 Sofrata A, Lingström P, Baljoon M, Gustafsson A. The effect of miswak extract on plaque $\mathrm{pH}$. An in vivo study. Caries Res 2007; 41: 451-454

7 Antonio AG, Moraes RS, Perrone D, Maia LC, Santos KRN, Iorio NLP, Farah $A$. Species, roasting degree and decaffeination influence the antibacterial activity of coffee against Streptococcus mutans. Food Chem 2010; 118: 782-788

8 Antonio AG, Iorio NLP, Pierro VSS, Candreva MS, Farah A, dos Santos KRN, Maia LC. Inhibitory properties of Coffea canephora extract against oral bacteria and its effect on demineralisation of deciduous teeth. Arch Oral Biol 2011; 56: 556-564

9 Matsumoto-Nakano M, Nagayama K, Kitagori H, Fujita K, Inagaki S, Takashima Y, Tamesada M, Kawabata S, Ooshima T. Inhibitory effects of Oenothera biennis (evening primrose) seed extract on Streptococcus mutans and S. mutans-induced dental caries in rats. Caries Res 2011; 45: 56-63

10 Almeida AAP, Farah A, Silva DAM, Nunan EA, Glória MB. Antibacterial activity of coffee extracts and selected coffee chemical compounds against enterobacteria. J Agric Food Chem 2006; 54: 8738-8743

11 Daglia M, Papetti A, Grisoli P, Aceti C, Spini V, Dacarro C, Gazzani G. Isolation, identification, and quantification of roasted coffee antibacterial compounds. J Agric Food Chem 2007; 55: 10208-10213

12 Ferrazzano GF, Amato I, Ingenito A, De Natale A, Pollio A. Anti-cariogenic effects of polyphenols from plant stimulant beverages (cocoa, coffee, tea). Fitoterapia 2009; 80: 255-262

13 Anila Namboodiripad PC, Kori S. Can coffee prevent caries? J Conserv Dent 2009; 12: 17-21

14 Daglia M, Papetti A, Dacarro C, Gazzani G. Isolation of an antibacterial component from roasted coffee. J Pharm Biomed Anal 1998; 18: 219 225 
15 Daglia M, Tarsi R, Papetti A, Grisoli P, Dacarro C, Pruzzo C, Gazzani G. Antiadhesive effect of green and roasted coffee on Streptococcus mutans' adhesive properties on saliva-coated hydroxyapatite beads. J Agric Food Chem 2002; 50: 1225-1229

16 Almeida AAP, Naghetini CC, Santos VR, Glória MB. In vitro antibacterial activity of coffee extracts on Streptococcus mutans. In: Propera, editors. Proceedings of the 20th International Conference on Coffee Science ASIC. Bangalore, India: ASIC; 2004: 242-248

17 Farah A, de Paulis T, Moreira DP, Trugo LC, Martin PR. Chlorogenic acids and lactones in regular and water-decaffeinated arabica coffees. J Agric Food Chem 2006; 54: 374-381

18 Perrone D, Donangelo CM, Farah A. Fast simultaneous analysis of caffeine, trigonelline, nicotinic acid and sucrose in green and roasted coffee by liquid chromatography - mass spectrometry. Food Chem 2008; 110: $1030-1035$

19 Lima YBO, Cury JA. Ingestão de flúor por crianças pela água e dentifrício. Rev Saude Publica 2001; 35: 576-581

20 Martins C, Siqueira WL, de Oliveira E, Primo LS, Nicolau J. Salivary analysis of patients with chronic renal failure undergoing hemodialysis. Spec Care Dent 2006; 26: 205-208

21 Beighton $D$. The complex oral microflora of high-risk individuals and groups and its role in the caries process. Community Dent Oral Epidemiol 2005; 33: 248-255

22 Parsek M, Singh PK. Bacterial biofilms: an emerging link to disease pathogenesis. Annu Rev Microbiol 2003; 57: 677-701

23 Dogasaky C, Shindo T, Furuhata K, Fukuyama M. Identification of chemical structure of antibacterial components against Legionella pneumophila in a coffee beverage. Yakugaku Zasshi 2002; 122: 487-494

24 Stauder M, Papeti A, Daglia M, Vezzulli L, Gazzani G, Varaldo PE, Pruzzo C. Inhibitory activity by barley coffee components towards Streptococcus mutans biofilm. Curr Microbiol 2010; 61: 417-421

25 Simonssen T, Glantz PO, Edwardsson S. Effects of cations on the colloidal stability of some oral bacteria. Acta Odontol Scand 1988; 46: 83-87
26 Rupesh S, Winnier IJ, Nayak UA, Rao UA, Reddy NV. Comparative evaluation of the effects of an alum-containing mouthrinse and a saturated saline rinse on the salivary levels of Streptococcus mutans. J Soc Pedod Prev Dent 2010; 28: 138-144

27 Hayacibara MF, Ambrozano GM, Cury JA. Simultaneous release of fluoride and aluminum from dental materials in various immersion media. Oper Dent 2004; 29: 16-22

28 Kleber CJ, Putt MS. Aluminium and dental caries. A review of the literature. Clin Prev Dent 1984; 6: 14-25

29 Marinho VC, Higgins JP, Logan S, Sheiham A. Topical fluoride (toothpastes, mouthrinses, gels or varnishes) for preventing dental caries in children and adolescents. Cochrane Database Syst Rev 2003; 4: CD002782

30 Marinho VC, Higgins JP, Sheiham A, Logan S. Combinations of topical fluoride (toothpastes, mouthrinses, gels, varnishes) versus single topical fluoride for preventing dental caries in children and adolescents. Cochrane Database Syst Rev 2004; 1: CD002781

31 Tenuta LMA, Cury JA. Fluoride: its role in dentistry. Braz Oral Res 2010; 24: 9-17

32 Marquis RE, Clock AS, Mota-Meira M. Fluoride and organic weak acids as modulators of microbial physiology. FEMS Microbiol Rev 2003; 26 : 493-510

33 Emilson CG. Potential efficacy of chlorhexidine against mutans streptococci and human dental caries. J Dent Res 1994; 73: 682-691

34 Bowen WH. Do we need to be concerned about dental caries in the coming millennium? Crit Rev Oral Biol Med 2002; 13: 126-131

35 Quivey Jr. RG, Kuhnert WL, Hahn K. Adaptation of oral streptococci to low pH. Adv Microb Physiol 2000; 42: 239-274

36 Vale GC, Tabchoury CP, Arthur RA, Del Bel Cury AA, Paes Leme AF, Cury JA Temporal relationship between sucrose-associated changes in dental biofilm composition and enamel demineralization. Caries Res 2007; 41: 406-412

37 Lemos JAC, Abranches J, Burne RA. Responses of cariogenic streptococci to environmental stresses. Curr Issues Mol Biol 2005; 7: 95-108 